\title{
LA VIVIENDA ENTERRADA: ESTUDIO DE SU EVOLUCIÓN TIPOLÓGICA Y ADAPTACIÓN GEOGRÁFICA
}

\author{
Beatriz Piedecausa García \\ Departamento de Construcciones Arquitectónicas \\ Universidad de Alicante
}

\section{RESUMEN}

La arquitectura subterránea ha dado cobijo y protegido al hombre desde muchos siglos atrás, evolucionando tipológicamente y perdurando con el paso del tiempo hasta llegar a la actualidad. La presente necesidad de incidir en planteamientos bioclimáticos hace indispensable el estudio de esta arquitectura más primitiva puesto que, además de formar parte de la vivencia colectiva del habitar humano, es un referente en cuanto al aprovechamiento de los condicionantes naturales de cada región gracias a propuestas arquitectónicas sencillas que se benefician de la inercia térmica del terreno. Al mismo tiempo, estas agrupaciones subterráneas plantean distintos modos de enfrentarse al territorio y a sus características geográficas, obteniendo soluciones urbanísticas y arquitectónicas trasladables a configuraciones actuales.

El objetivo del presente artículo es poner de manifiesto la evolución tipológica de la vivienda enterrada a nivel mundial, tanto como solución arquitectónica como sistema de agrupación urbanístico, así como plasmar su nivel de adaptación a la geografía regional en cada caso.

Palabras clave: vivienda enterrada, tipología de excavación, trogloditismo, confort, inercia térmica, adecuación geográfica, hábitat primitivo internacional.

\begin{abstract}
Underground architecture has sheltered and protected man from many centuries ago, by a typological evolution and by enduring over time into the present. The current need to emphasize bioclimatic approaches makes essential the study of this primitive architecture, due to the fact that this architecture is a part of the collective human living experience but also a reference in using natural conditions of each region through simple architectural proposals based on ground thermal inertia. In addition, these underground groups propose different modes to deal with the territory and its geographical features, obtaining urban and architectural solutions transferable to current configurations.
\end{abstract}


The aim of this paper is to show the typological evolution of the excavated dwelling worldwide, as an architectural proposal and as an urban solution, and also to show its adaptation level to the regional geography in each case.

Key words: buried house, excavation typology, troglodytism, comfort, thermal inertia, geographical suitability, primitive international habitat.

\section{La otra arquitectura: de la cueva a la monumentalidad egipcia}

Durante muchos años, y hasta una época muy reciente, tanto ciertos historiadores como arquitectos han compartido la opinión de que los orígenes de la producción arquitectónica se remontan, fundamentalmente, al periodo egipcio hace más de 5.000 años. Sin embargo, esta visión dejaba de lado todo el ámbito de la arquitectura popular que, anteriormente a esa gran civilización, había dado cobijo y acogido al hombre desde muchos siglos atrás, y olvidaba construcciones que evolucionarían y perdurarían con el paso del tiempo, llegando incluso hasta la actualidad. Debido a esto, el presente trabajo se basa en la convicción de que es necesario tener en cuenta también este otro tipo de arquitectura más primitiva, ya que a pesar de no poder competir frontalmente con las citadas arquitecturas egipcias monumentales, también forma parte de la vivencia colectiva del habitar humano.

De este modo, el punto de arranque se basa en el estudio del primer hábitat permanente utilizado por el hombre primitivo, la cueva. Un elemento natural donde se encontraba protección de la lluvia o del frío en invierno, del sol o el calor en verano, sirviendo incluso de protección frente a agresiones de animales salvajes o de otras tribus. Probablemente durante muchos años no realizó ninguna alteración de estos espacios pero, con el transcurrir del tiempo, el hombre aprendió a modificarlas a su conveniencia: allanó los suelos, agrandó las cavidades naturales o excavó nuevos espacios vinculados a los ya existentes, y fue en ese preciso momento cuando realmente comenzó a hacer arquitectura.

Por tanto, el proceso mediante el cual estas cuevas naturales fueron utilizadas con fines de habitar, donde resguardarse de las inclemencias del tiempo, para pasar poco a poco a modificarse lentamente, mejorando las condiciones iniciales de los espacios y generando propuestas constructivas, es en sí un primer proceso de intervención arquitectónica. Actuaciones primitivas que sirvieron de base para que posteriormente aparecieran excavaciones suplementarias o pequeñas construcciones exteriores dando como resultado mejoras en las condiciones bioclimáticas y en la intervención en un entorno construido.

\section{Trogloditismo arquitectónico: soluciones globales a problemas concretos}

En un primer momento, probablemente exista en el sentir popular una idea preestablecida respecto a las construcciones trogloditas, considerando que no poseen un alto grado de contribución intelectual y, por tanto, que no merecen catalogarse como soluciones propiamente arquitectónicas, puesto que su ejecución no se basa en conocimientos conceptuales complejos, cumplimientos normativos o técnicas avanzadas.

A pesar de esto, los distintos casos analizados en el siguiente trabajo, cada uno englobado dentro de una tipología concreta, demostrarán cómo estas arquitecturas se convierten en muchas ocasiones en grandes soluciones. Por tanto, sería un comportamiento demasiado superficial el despreciar, de un modo tajante y sin argumentos, este tipo de consideraciones incluso en la actualidad, puesto que muchos de los conceptos arquitectónicos empleados en esas construcciones más iniciales podrían aplicarse a arquitecturas subterráneas contemporáneas. En esa misma línea, Rudofsky (2002: 20) añade: «El trogloditismo no implica necesariamente un bajo nivel cultural. La imagen del hombre 
de las cavernas arrastrando a su compañera por su pelo es un cliché caricaturesco, que traiciona la nostalgia de tiempos pasados, en lugar de un retrato de una clase de personas que prefieren vivir bajo tierra» ${ }^{1}$.

Como introducción a este tipo de arquitectura, las primeras impresiones de ser una solución poco interesante o incluso algo vacía de significado cambiarán por completo si se consideran, por ejemplo, las excavaciones irregulares del oasis de Siwa, en Egipto, consistentes en la ocupación como viviendas de distintas entradas a las tumbas de un antiguo cementerio, o si se consideran ciertos refugios excavados de una manera mucho más sofisticada como pueden ser el conjunto de viviendas subterráneas de Luoyang, en China. Desde este momento, el interés por aspectos bien formales, bien espaciales o incluso geométricos que puede llegar a ofrecer este tipo de arquitectura, comienza a despertarse gracias a atractivas soluciones como éstas.
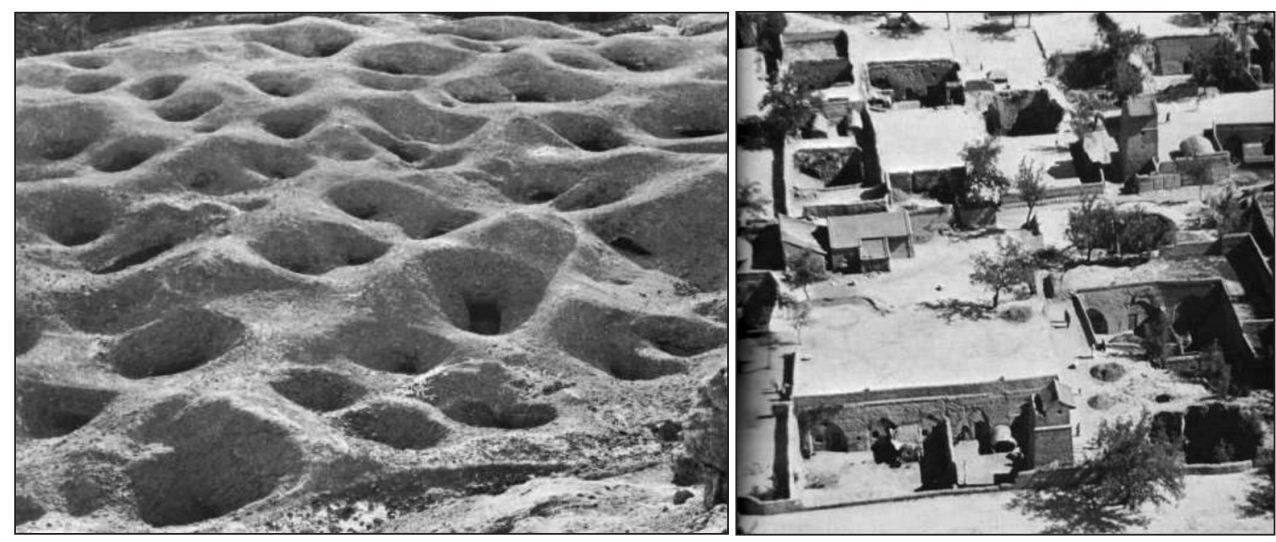

Figura 1: Imagen izquierda: Oasis de Siwa. Egipto. Imagen derecha: Viviendas excavadas. Luoyang. China.

Fuente: Rudofsky (2002: 20).

Evolutivamente, tras el paso del nomadismo al sedentarismo, los primeros habitantes de grutas naturales no disponían de los enseres ni las técnicas pertinentes para modificar de una manera sustancial la configuración del territorio en el que habían decidido vivir. Debido a esto, la selección del lugar se basaba en condicionantes variables como la buena visibilidad perimetral, la ubicación junto a rutas significativas, una orientación favorable o la posibilidad de ampliación de determinadas actividades. Dependiendo de las condiciones exteriores del entorno o las internas del terreno, las cuevas iniciales excavadas de un modo sencillo fueron convirtiéndose en sistemas más complejos que distinguían estancias y usos.

1 RUDOFSKY, Bernard: Architecture without architects. A short introduction to non-pedigreed architecture. University of New Mexico Press. 7 a edición. Albuquerque, 2002. Pág. 20.

Texto original: "Troglodytism does not necessarily imply a low cultural level. The picture of the caveman dragging his mate by her hair is a cartoonist's cliché, betraying nostalgia for bygone days, rather than a portrait of the kind of people who prefer to live below ground». 
Esta variedad de espacios permitía un habitar diferente según distintas condiciones climáticas exteriores o periodos de ocupación. Al respecto, Shoenauer (1984: 27) afirma que «La característica principal de la casa, en una sociedad más avanzada de cazadores y pescadores, es su adaptación a unas condiciones climáticas adversas», y para ello es necesario un control climático más sofisticado, existiendo en muchos casos agrupaciones excavadas con dos tipologías distinguibles, una para invierno y otra para verano.

Por tanto, la relación entre hábitat y habitante se muestra como un vínculo de impresionante riqueza trasladable también a la dependencia entre el propio territorio y las distintas construcciones troglodíticas que en él se implantan, permitiendo una respuesta específica ante situaciones y necesidades diversas.

Este tipo de arquitectura troglodítica se podría clasificar en cuatro subtipos principales en función de la dirección de la excavación: Arquitecturas de excavación horizontal, Arquitecturas de excavación vertical, Arquitecturas de excavación superficial y Arquitecturas de excavación horizontal+vertical.

Teniendo en cuenta que en esta clasificación se han considerado como cuevas todo aquel hábitat troglodita enterrado, semienterrado o cubierto total-parcialmente de tierra, a continuación se procede al análisis de distintas tipologías y al estudio de ejemplos concretos construidos de cada una de ellas, mostrando en cada caso su intención y morfología concreta.

\subsection{Arquitectura como corrección del relieve natural: la excavación horizontal}

Pertenecen a este grupo las tipologías en las que existe una mínima intervención del hombre en la configuración del espacio habitable, y se fundamentan en el acondicionamiento básico de cavernas naturales mediante sencillas intervenciones arquitectónicas. Estas intervenciones pueden ser, bien la excavación de espacios en un frente montañoso o bien el cierre de otros más interiores mediante algún tipo de cerramiento espontáneo, amoldándose a lo existente y retocando sutilmente aquello que desde la naturaleza les había sido ofrecido.

Esta arquitectura corresponde al hábitat más primitivo y, por tanto, se puede considerar como una arquitectura improvisada o como una construcción con posibilidad de cambio con el paso del tiempo. Debido al uso de la roca existente como material base, únicamente es necesario ir profundizando con la excavación poco a poco, pudiendo alterarse tanto el tamaño como la forma de la estancia, eso sí, siempre dentro de unos límites estructurales relacionados con el tipo de terreno.

De este modo, la construcción se va amoldando a las necesidades de espacio de cada momento, convirtiéndose en un elemento «elástico» debido a que se puede modificar la organización de las estancias. Incluso pueden aparecer otras nuevas a medida que vayan siendo necesitadas, aunque debe tenerse en consideración que no es posible una modificación total de los espacios, sino únicamente es viable la ampliación mediante la excavación de masa rocosa existente. A este respecto, Algarín (2006: 33) confirma que es posible un cambio de uso mediante la modificación de las diferentes salas, dando lugar a una arquitectura más personalizada en la que: "[...] se pierde la habitual división horizontal, pues las ampliaciones y conexiones pueden realizarse con cualquier altura y partiendo y llegando a cualquier cota, con el único condicionante para el ocupante de la comodidad al trazar las escaleras y rampas».

Debido a que el proceso constructivo de excavación es irreversible y a que estos espacios se ejecutan poco a poco pero con gran esfuerzo, la arquitectura avanza progresivamente en un proceso continuo. Arquitectura que se muestra, al mismo tiempo, algo insegura y 
cambiante a la vez que firme, másica y pesada. Arquitectura en proceso, de desarrollo in situ, que no necesita ser dibujada ni plasmada en planos, puesto que se apoya únicamente en la materia existente. Arquitectura permanente al paso del tiempo y a la vez adaptable a nuevos requerimientos espaciales, considerando que, tal y como afirma Rudofsky (2002: 19) al respecto, «La durabilidad y la versatilidad son las características de la arquitectura vernácula» ${ }^{2}$.

Por otra parte, si se analiza un caso concreto como es la ciudad troglodítica de Pantalica en Sicilia (Italia), es posible encontrar pequeños y rudos espacios excavados por los Siculi, quienes habitaban en la isla hace unos 3.000 años, en laderas prácticamente verticales del valle de Anapo.

Tal y como recoge Rudofsky (2002: 19) en su libro Architecture without architects, estas construcciones surgieron tras la repoblación de un cementerio prehistórico adyacente que durante la Edad Media fue reconvertido en viviendas estables. Construcciones en las que la roca podía trabajarse vertical y horizontalmente, uniendo cuevas individuales mediante pozos o pasadizos gracias a una red de túneles y cámaras, formando estancias ubicadas en diferentes pisos conectados por pasajes interiores. Estos asentamientos se establecen de un modo similar repartidos por toda Sicilia: cerca de Caltabellotta y Raffadali, al oeste del volcán Etna; cerca de Siracusa y sobre todo, en el valle de Ispica, cerca de Modica.
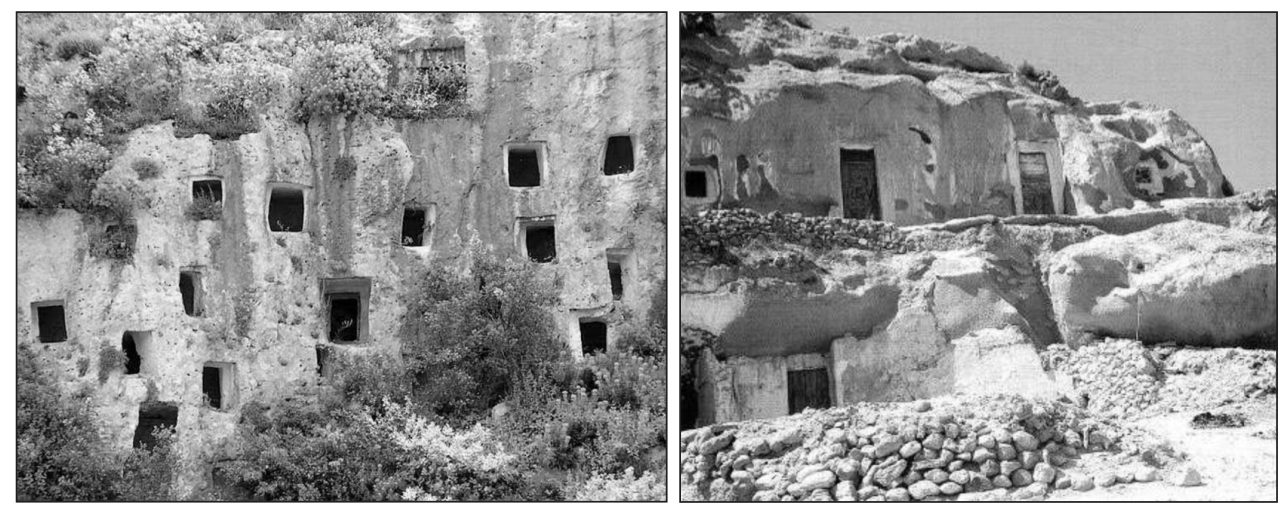

FIGURA 2: Imagen izquierda: Viviendas excavadas en la roca en Pantalica. Sicilia. Italia. Fuente: www.archeologia.com. Imagen derecha: Cuevas de Almanzora. Andalucía. España. Fuente: Oliver (2007: 87).

Dentro de este apartado, también pueden incluirse todas aquellas construcciones basadas en el acondicionamiento bien de grutas existentes o bien de básicas excavaciones en las laderas de montañas, como ocurre en ejemplos de distintos puntos de la geografía española, más específicamente en el sur. En estos lugares existen condicionantes geológicos y climáticos muy parecidos, lo que lleva a una similitud en materiales y técnicas de la construcción, aunque el tamaño y el desarrollo de la vivienda varían dependiendo del

2 RUDOFSKY, Bernard: Architecture without architects. A short introduction to non-pedigreed architecture. University of New Mexico Press. $7^{\text {a }}$ edición. Albuquerque, 2002. Pág. 19.

Texto original: «Durability and versatility are characteristic of vernacular architecture». 
emplazamiento concreto. En los territorios españoles, existen dos tipos de comunidades de particular interés al respecto, como son por una parte el pueblo troglodita de Guadix, cerca de Granada, que se beneficia de las cualidades de la tierra como aislante y elemento protector, al tiempo que aprovecha su inusitado ambiente natural para constituir un conjunto de gran plasticidad. Y por otra parte, la comunidad subterránea de Cuevas de Almanzora, que está compuesta por hileras horizontales de viviendas excavadas desde el Paleolítico, con diversos niveles localizados en un escarpe rocoso. Se trata de un numeroso conjunto de cuevas, excavadas en la roca y utilizadas como viviendas, incluso algunas de ellas todavía en la actualidad. Estas excavaciones horizontales responden directamente a la estructura de la cueva espontánea, y debido a su similitud con las grutas naturales y a su mayor simplicidad son las que han tenido un desarrollo más continuado, siendo las tipologías más habituales hoy en día y en ocasiones complementadas con construcciones exteriores adosadas.

\subsection{Arquitectura enterrada en el subsuelo: la excavación vertical}

Este grupo de arquitecturas lo forman aquellas en las que el sentido de excavación es vertical, horadando el subsuelo desde la superficie. Dentro de este conjunto, se pueden englobar ciertos hábitats prehistóricos de China, con distintas arquitecturas enterradas en las provincias de Honnan, Shensi y Kansu, todas ellas en terrenos compuestos por loess. Estos territorios están formados por limos, un material sedimentario arcilloso, de color amarillento y de origen eólico que en su día fue transportado y depositado por el viento. Material de alta porosidad (45\%), que puede ser fácilmente tallado y que posee una dureza suficiente para resistir la erosión permitiendo a la vez ser trabajado y excavado por el hombre, aprovechando al máximo sus interesantes cualidades mecánicas.

Desde el Neolítico, es en China donde se encuentran las primeras viviendas primitivas excavadas en forma de «saco», que según Loubes (1985: 39) probablemente puedan considerarse como la forma más antigua de vivienda prehistórica que se conoce hasta la actualidad en esa región. En estas arquitecturas la excavación se realiza verticalmente en el terreno, dando como resultado unas construcciones de planta circular, en las que el diámetro inferior es mayor que el superior, tallando el hueco de acceso mediante una sección cónica que ofrece cierta protección frente a las condiciones climáticas.

Eran unas primeras arquitecturas de dimensiones reducidas aunque suficientes, con una profundidad de $3 \mathrm{~m}$, una diámetro interior de $4 \mathrm{~m}$ y uno en superficie de unos $3 \mathrm{~m}$ aproximadamente, abiertas por la parte superior en la mayor parte de los casos. Esta dificultad a la hora de construir un techo limita las dimensiones del abrigo, en contraposición con la facilidad de excavación que ofrece el loess como material que permite afianzar la construcción mediante paredes cóncavas en el interior.

Con el paso del tiempo y con la evolución de herramientas constructivas, las paredes comienzan a aplomarse, reduciéndose el peligro de desmoronamiento; además la forma de la excavación empieza a ovalarse, facilitando el aumento de dimensiones y la aparición de estructuras de cubierta, dando lugar a construcciones más complejas y más espaciosas. Por tanto, es un tipo de arquitectura que podríamos considerar como un elemento cerrado y ciego, que se refiere a sí mismo, a su masividad y estructura. Una construcción que en la mayoría de los casos únicamente se estructura gracias al descubrimiento paso a paso del espacio interior, sin saber qué deparará el proceso de excavación, ya que no se emplean técnicas de reconocimiento del terreno, tan comunes en la actualidad. No existe un estudio previo, tan sólo el saber popular y la experiencia aprehendida ubican la arquitectura en su entorno. 

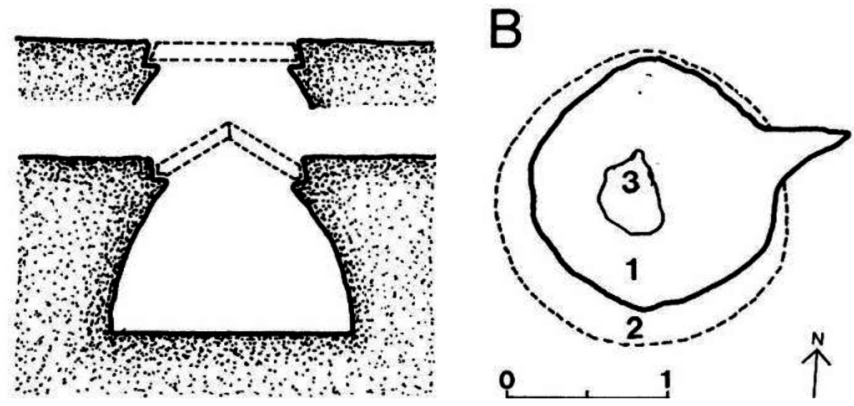

1. Diámetro superior

2. Diámetro inferior

3. Posición del hogar

FIgURA 3. Imagen izquierda: Sección vivienda del neolítico excavada en «saco» con dos hipótesis sobre la forma de cobertura temporal. Imagen derecha: planta de una vivienda excavada en «saco». Pueblo de Jing. Provincia de Shanxi. China.

Fuente: Loubes (1985: 20).

Unas de las construcciones troglodíticas englobadas dentro de este apartado son las arquitecturas desarrolladas en distintas ciudades en el norte de China. Excepcionales conjuntos arquitectónicos que necesitan de un estudio pausado, puesto que a primera vista podrían parecer construcciones desarrolladas mediante una solución de cubierta plana, cuando en realidad, son espacios excavados completamente en el propio terreno natural. Se trata de una solución repetida de una manera sistemática, habitual en zonas sin accidentes geográficos importantes, fruto de una larga evolución a lo largo del tiempo y que da lugar a un gran conjunto de viviendas excavadas en el loess. Agrupaciones unitarias que albergan a más de diez millones de personas y que contemplan incluso la posibilidad de futuras ampliaciones.

En resumen, y recogiendo las afirmaciones de Loubes (1985: 39), es posible distinguir la existencia de una doble evolución a partir de estas arquitecturas tan iniciales:

A) A medida que van evolucionando los materiales posibles a utilizar, las técnicas y herramientas manejadas, la vivienda va saliendo del suelo (Capadocia).

B) La vivienda permanece enterrada en el subsuelo, pero debido a las nuevas técnicas evoluciona hacia una mayor complejidad, llegando a la aparición de todo un urbanismo enterrado (China y Túnez).

Ambos ejemplos serán estudiados con detenimiento en los apartados siguientes.

\subsection{Arquitectura sustractiva: la excavación superficial}

Este tipo de intervención troglodita se obtiene a partir de la excavación sobre elementos rocosos existentes en superficie, creando nuevas configuraciones y espacios por encima de la línea de tierra. Dichas construcciones no se limitan únicamente a disfrutar de la propia disposición natural del entorno, sino que implican una excavación mayor, siendo necesarias unas condiciones de dureza del terreno para una mínima resistencia, al tiempo que es lo suficientemente blando como para ser excavado y modelado con herramientas rudimentarias (por ejemplo, terrenos de creta). 
Arquitecturas por encima de la cota cero, excavadas en el interior de formaciones rocosas en superficie sobre las que, en muchas ocasiones, los hombres han tallado pueblos enteros en la roca natural. Dentro de este tipo de excavación, podemos encontrar ejemplos de arquitectura sustractiva tanto en Francia como en Turquía. La mayor parte de la ciudadela de Les Baux-en-Provence (Francia), con sus murallas, castillos y casas fueron esculpidos en la montaña calcárea sobre la cual se encuentran; convirtiéndose en un lugar importante en la Edad Media para, posteriormente, pasar a ser durante mucho tiempo una arquitectura abandonada. Otro ejemplo bastante ilustrativo de este tipo de arquitectura son los conos excavados en la región de la Capadocia, en Turquía. Se trata de una ciudad troglodítica ubicada en el valle de Göreme, en la que se encuentran una sucesión de toscos espacios perforados en paredes de roca prácticamente verticales, constituyendo otro ejemplo concreto de arquitectura sustractiva en pináculos horadados. Agrupaciones que engloban un amplio rango de construcciones, dentro de un intervalo que abarca desde el tamaño de una pequeña tienda a elementos que incluso podrían asemejarse a pequeños rascacielos compuestos por la nada despreciable cifra de 16 pisos; encontrando desde cuevas simples más rudimentarias, hasta incluso cuevas en doble y triple nivel.
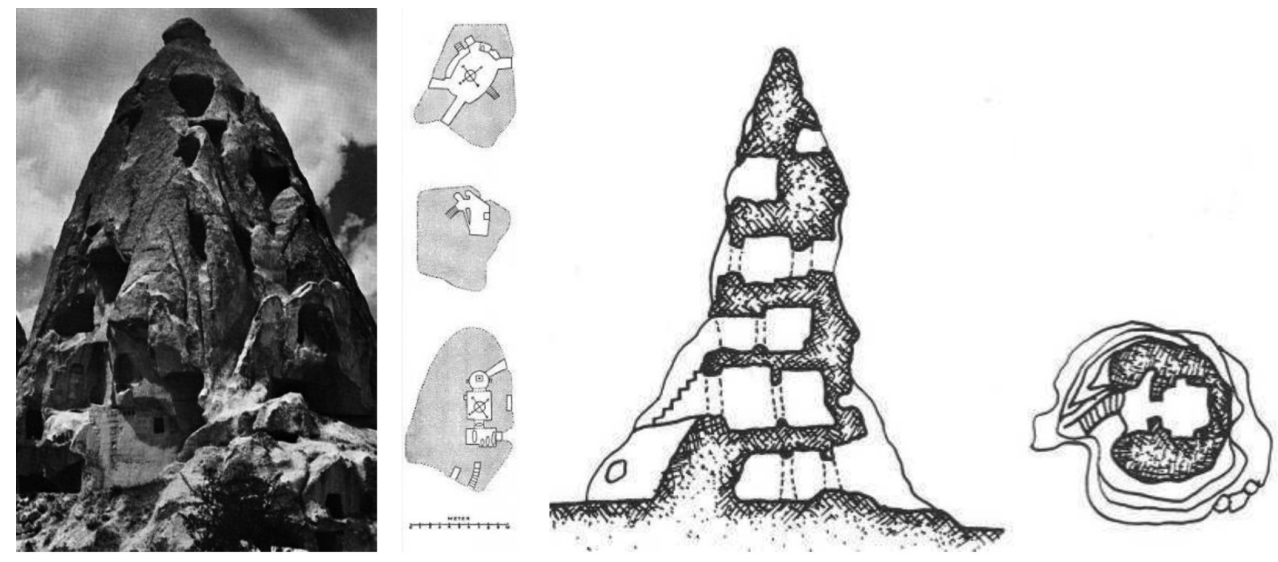

FIgura 4: Imagen izquierda: Conos del valle de Göreme. Capadocia. Turquía.

Fuente: Rudofsky (2002: 27). Imagen derecha: Valle de Avcilar. Capadocia. Turquía. Fuente: Neila (2004: 408).

Respecto a las condiciones del emplazamiento, por sí mismo parece hacer un llamamiento a personas con un deseo de aislamiento y retiro. Y no es en vano, puesto que durante el siglo VII unos 30.000 eremitas, entre hombres y mujeres, constituyeron aquí una gran comunidad monástica ocupando cuevas en los pináculos que, a pesar de ser formas primitivas sin demasiadas facilidades funcionales, permitieron albergar miles de cámaras, iglesias y capillas, a las que curiosamente se accedía mediante rudimentarias escalas de cuerda. Debido a la facilidad del trabajo manual sobre este tipo de terreno, concretamente toba volcánica, el material hace posible esculpir en el propio paramento gran parte del mobiliario y la decoración (muebles, tarimas, estantes, alacenas o asientos), incorporándolos 
inicialmente, desde la misma ejecución de la estancia. De este modo, existe un elemento más que repercute en la planificación de la construcción de dichos espacios, debiendo manejar varios parámetros simultáneamente en el proceso de excavación y dando lugar a una organización más compleja.

En resumen, en este tipo de arquitecturas el ser humano aprovecha la roca para excavar sus propias viviendas, ahorrando de este modo gastos de recolección, transporte y ensamblado de materiales constructivos. A este respecto, y realizando una comparativa entre las construcciones animales con las propias de los humanos, Omedes y Piqué (2003: 132) añaden que: «La economía de una construcción viene determinada por la relación entre el coste y la efectividad. Una construcción es económica cuando satisface una necesidad (aislamiento, climatización, protección [...] con costes bajos». Donde los autores enfatizan que, al igual que ocurre en la actualidad con determinadas soluciones arquitectónicas, la repercusión general de un proceso de difícil ejecución o la utilización de un material concreto, será rentable no por su coste relativo sino por su eficiencia global. Un concepto que puede ser trasladable al caso de los Conos de Capadocia, en los que a pesar de la dificultad inicial de excavación tanto de huecos como de mobiliario, el esfuerzo valió la pena y así ha dejado constancia de ello a lo largo de los años.

\subsection{Arquitecturas combinadas: la excavación mixta}

En un principio, este tipo de excavaciones mixtas aparecieron como necesidad de constituir desarrollos en lugares donde no existían elementos montañosos con pendientes adecuadas para excavar cuevas horizontales. Por tanto, debido a la plana orografía, era posible excavar únicamente en dirección vertical hacia el subsuelo, con los consiguientes inconvenientes que ello exigía.

Como ya se ha comentado previamente, las cuevas verticales eran excavaciones muy rudimentarias y bastante poco exitosas, puesto que tenían problemas tanto de excavación como de protección frente al viento, al agua y el sol. Por tanto, con el fin de evitar estos inconvenientes, se generó un nuevo patrón de excavación basado en la síntesis de otros dos tipos ya comentados: la excavación vertical más la excavación horizontal. Dicho sistema comenzaba abriendo inicialmente un patio excavado en vertical para llegar a un nuevo plano horizontal y una vez se habían generado paredes en el perímetro del hueco se excavaba horizontalmente alrededor de este vacío, como si de una cueva excavada en la montaña se tratase. Solución que ha generado una considerable diversidad de formas y pueblos, cada uno respondiendo a sus diferencias climáticas y geográficas, llegando a ser, en algunos casos, las más originales estructuras trogloditas de toda la comarca mediterránea, como ocurre en las agrupaciones de viviendas de Matmata, en Túnez.

A pesar de que en este tipo de excavación en el terreno la vivienda ofrece algunos peligros añadidos en caso de infrecuentes temporales de agua, esta configuración realmente permite un mayor aprovechamiento de las características más interesantes de cada sistema por separado.

Por una parte, la excavación vertical permite una profundización en el terreno para llegar a una cota de uso protegida de los vientos frecuentes, permite agrupaciones que pasan desapercibidas en el paisaje, camuflándose frente a enemigos y permite una iluminación más bien indirecta gracias al patio excavado. Por otra parte, la excavación horizontal favorece un aislamiento térmico en cubierta, debido a la gran inercia térmica que ofrece el terreno y permite una mayor facilidad funcional al establecer relaciones verticales entre distintos niveles de estancias. 

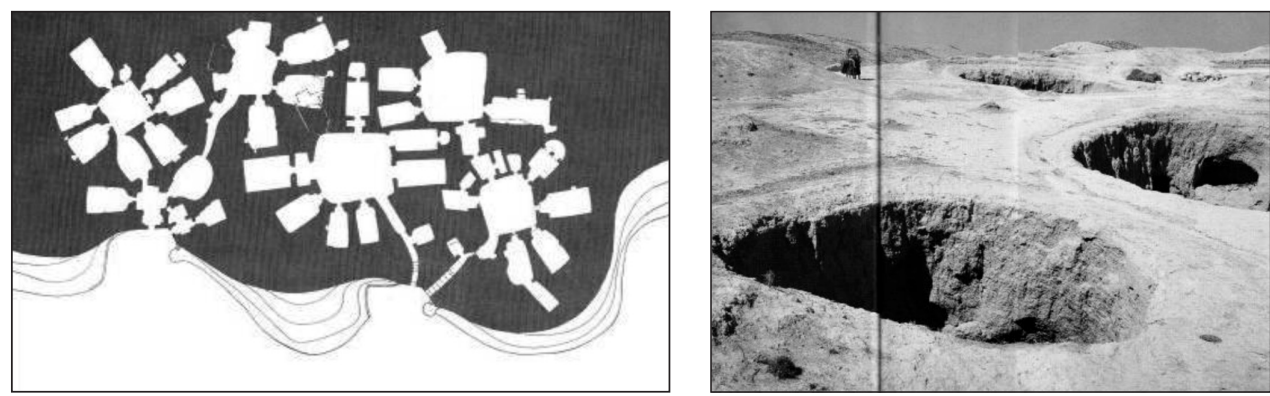

FiguRA 5. Imagen izquierda: Cráteres subterráneos en Matmata. Túnez. Imagen derecha: Plantas de viviendas en Matmata. Túnez.

Fuente: Goldfinger (1993: 156-157).

Esta construcción mixta es el tipo más frecuente si hablamos de vivienda troglodita enteramente artificial, sin aprovechamiento de elementos preexistentes. Espacios que se ahondan en la tierra alrededor de grandes huecos con una disposición de habitaciones diferenciadas a lo largo de su perímetro. Estas grandes excavaciones hechas por el hombre constituyen una de las soluciones de vivienda troglodíticas más avanzadas e incluso en palabras de Goldfinger (1993: 152) son «los sistemas más económicos de vivienda creados por el ser humano».

Esta catalogación de cuevas se distribuye a lo largo de toda la geografía mundial, formando agrupaciones donde los pozos excavados de forma mixta determinan la unidad de vivienda o el grupo sociológico básico, como es el caso de comunidades en Túnez, España o China. Unas de las construcciones troglodíticas con mayor importancia que se incluyen dentro de este apartado de excavación mixta son las arquitecturas desarrolladas en la ciudad subterránea de Matmata, en el sur de Túnez, donde existe una destacada variedad de viviendas excavadas en mesetas. Estas unidades urbanas de dimensiones significativas, forman importantes cavidades en las que viven un centenar de personas, llegando incluso a dimensiones de $60 \mathrm{~m}$ de diámetro por $10 \mathrm{~m}$ de profundidad. Estas medidas provocan la necesidad de utilización de escaleras bien talladas en el terreno o bien formadas por piezas de madera empotradas en la pared para acceder a las habitaciones del piso superior. Del mismo modo, desde el fondo del pozo existe una conexión entre los distintos niveles mediante largos túneles en pendiente que comunican el fondo con la superficie.

Dentro de las construcciones excavadas mixtas, existen otras agrupaciones en regiones lejanas, con condiciones ambientales completamente antagónicas pero que, sin embargo, responden de una manera muy similar frente a requerimientos diferentes, como es el caso de viviendas en Luoyang (China), donde la cueva excavada en el terreno se convierte en la vivienda del campesino pobre, gracias a que puede ser construida con escasos medios. Una de las soluciones más radicales en el ámbito de estos refugios excavados se encuentra representada por las ciudades y aldeas subterráneas en la zona de loess de China, ya que debido a la existencia de este material de alta porosidad puede tallarse fácilmente.

En dichas agrupaciones orientales, la disposición en planta de la vivienda es rectangular, con los hogares y estancias principales organizadas en excavación horizontal desde las paredes del patio, teniendo siempre un espesor de terreno por encima de la gruta como mínimo de $3 \mathrm{~m}$, a fin de estar protegidos contra las infiltraciones del agua de lluvia. Las paredes verticales de las viviendas poseen una altura entre $7 \mathrm{~m}$ a $9 \mathrm{~m}$ por el exterior, mientras que 
las habitaciones interiores tienen unas dimensiones de alrededor de $9 \mathrm{~m}$ de profundidad, $4.5 \mathrm{~m}$ de ancho y otros $4.5 \mathrm{~m}$ de alto hasta la parte superior de la bóveda, bien iluminadas y ventiladas por aberturas que dan al patio.

Contrariamente a lo que en un primer momento podría parecer, estas viviendas subterráneas mantienen unas condiciones de habitabilidad bastante salubres y constituyen una solución cálida en invierno y fresca en verano. Tanto es así, que en China, esta solución ha llegado a establecerse como solución global aplicable no sólo a las viviendas, sino también a fábricas, escuelas, hoteles o incluso a oficinas de gobierno que están construidas enteramente bajo tierra.

Respecto a la configuración del conjunto, los patios cuadrados abiertos en el llano terreno existente liberan un área de unos $500 \mathrm{~m}^{2}$. Esta configuración de viviendas abajo y campos arriba constituye un aprovechamiento al máximo de la superficie debido a que los espacios habitables no ocupan terreno cultivable.

Finalmente, si establecemos una comparativa entre ambas agrupaciones, en primer lugar se puede concluir respecto a una cuestión geométrica que, mientras las excavaciones en China se rigen por la ortogonalidad de sus construcciones, generando huecos cuadrados en un terreno llano, en Túnez prima la aleatoriedad de las formas, apostando por agrupaciones más orgánicas que pasan desapercibidas en el terreno. En palabras de Loubes (1985: 90) si comparamos la morfología de ambos tejidos comprobamos que ambos poseen una organización muy rigurosa pero cabe destacar ciertos matices formales, ya que la geometría: "[...] es abstracta en el caso de China, donde a menudo se relaciona con una trama sistematizada. En cambio es más aleatoria y más libre en Túnez, donde predominan las formas elásticas en el corte de las cuevas».

En segundo lugar, respecto a la facilidad de la excavación cabe decir que la penetración profunda bajo tierra es posible por la gran facilidad de vaciado que ofrece trabajar con los materiales disponibles en cada territorio. Por una parte la roca arenosa seca en Túnez es un material que aparentemente se asocia con la disgregación pero que muestra una compacidad y resistencia apta para una construcción excavada. Por otra, en el caso del loess en China ya se ha comentado que es un material de alta porosidad pero con facilidad para ser excavado y para proteger de los cambios del ambiente exterior.

Y por último, respecto a la idoneidad de una misma solución para dos climas tan dispares, cabe decir que mientras que en Matmata el clima es sumamente caluroso en verano, en Henan lo es muy frío, con temperaturas bajo cero. Aún así, en ambos ha prosperado de una manera muy satisfactoria el mismo tipo de arquitectura subterránea, demostrando que es tan apta para calor como para el frío, llegando a asumir una gran oscilación térmica diaria, que en ambas partes del mundo supera $\operatorname{los} 20^{\circ} \mathrm{C}$. Por tanto se puede concluir al respecto que, tal y como expone Loubes (1985: 90): «[...] una misma técnica de excavación y la misma situación en relación con la superficie del terreno, han conducido a expresiones totalmente diferentes» distintas combinatorias de las tipologías nombradas anteriormente, ya que los arquitectos trogloditas han intentado adaptar al máximo estas disposiciones elementales enriqueciendo enormemente el resultado.

En definitiva, los pueblos excavados constituyen un atractivo ejemplo de urbanismo subterráneo que ha logrado resolver de un modo muy interesante la abertura de las construcciones hacia el clima exterior logrando un beneficio térmico gracias, bien a la inercia térmica de grandes muros de terreno natural o bien mediante la creación de espacios colchón, tal y como ocurre con la generación de pozos centrales en las arquitecturas excavadas. Espacios que, al tiempo que distribuyen y organizan las habitaciones de la vivienda, aseguran la penetración indirecta de luz y calor de un modo muy confortable. 


\section{Trogloditismo urbano: el territorio como materia a esculpir}

El desarrollo del urbanismo primitivo se basa, fundamentalmente, en el de una unidad aislada, la vivienda. Esa unidad mínima fue desarrollada primordialmente como abrigo para el hombre, primero en un único y simple espacio y posteriormente, a medida que la vida fue haciéndose más compleja y las exigencias aumentaron, fueron surgiendo unidades adicionales respecto al volumen básico, vinculadas a la principal de un modo muy concreto y que conformaban estructuras cada vez más complejas y de mayores dimensiones.

Desde un principio, las excavaciones evolucionaron a partir de las exigencias internas del espacio y del propio tamaño de la vivienda, con formas y aberturas que reflejaban funciones específicas, pero sin duda las influencias exteriores a la propia unidad y la relación entre ellas también afectaron al plan organizativo. Resultó muy ventajoso para los grupos trogloditas unirse entre ellos para la defensa colectiva o el trabajo común $\mathrm{y}$, en la mayor parte de los casos, formaron comunidades aisladas en el territorio, que intentaban funcionar de una manera lo más autónoma posible, unidas en hileras o constituyendo racimos de casas.

Esta nueva relación social, bidireccional entre los miembros de la agrupación, limitó la expansión de la unidad debido a la necesidad de protección, pero a la vez pudo aportar a la comunidad ventajas mayores que las del único propósito de aislamiento, generando materiales y herramientas comunes y compartidas. Esta vida en comunidad, con el paso del tiempo fue derivando en que la casa adquiriera una nueva función, la de facilitar al hombre un mayor grado de intimidad pero ahora no por necesidad de protección respecto al entorno exterior sino respecto al resto de componentes de la agrupación a la que pertenece.

La necesidad de seguridad de aquellos habitantes condicionaba la tendencia de construir agrupaciones en emplazamientos con una importante dificultad de acceso; pero al mismo tiempo, esta decisión puede relacionarse, sin duda, incluso aún más con la necesidad de definir un perímetro delimitado y reconocible por la propia comunidad.

Tal es así que desde el mundo antiguo muchas ciudades están aún hoy cercadas por fosos, lagunas, acantilados o incluso paredes que hace ya tiempo perdieron su valor defensivo, hasta el punto que según Rudofsky (2002: 11) muchos arquitectos modernos: «[...] imaginan las ciudades subterráneas bajo la hipótesis optimista de que puedan protegernos de los peligros de la guerra del futuro, estas ciudades existían, y aún existen, en más de un continente ${ }^{3}$.

Por tanto, no es absurdo afirmar que muchos de los orígenes de los poblados troglodíticos estudiados surgen de la protección frente a ataques enemigos, tal y como ocurre en el caso concreto del espectacular desarrollo de los paisajes troglodíticos de Capadocia (Turquía), resultado de la emigración cristiana en el siglo VII hacia el Oeste, tras huir de la presión musulmana.

Las ciudades de Kayseri, Nidge y Kirsehir forman un triángulo que sitúa en la región de Anatolia Central las agrupaciones más destacadas y concentradas de estos conjuntos trogloditas, tanto superficialmente en el valle del Göreme, como mediante la creación de ciudades subterráneas como son Derinkuyu y Kaymakli, ambas destacadas entre las cuatro existentes en la zona.

3 RUDOFSKY, Bernard: Architecture without architects. A short introduction to non-pedigreed architecture. University of New Mexico Press. $7^{\text {a }}$ edición. Albuquerque, 2002. Pág. 11.

Texto original: "[...] envisioned subterranean towns under the optimistic assumption that they may protect us from the dangers of future warfare, such towns existed, and still exist, on more then one continent». 
En conclusión, desde un principio los diversos sistemas comunitarios se desarrollaron como consecuencia de requerimientos sociales como podían ser exigencias de grupos familiares, de la organización comunitaria o de los medios de vida de los habitantes; aunque también estas agrupaciones son consecuencia de las características locales o regionales como podían ser el clima, la topografía o los materiales disponibles.

Del mismo modo que se han clasificado anteriormente los distintos tipos de arquitectura troglodítica en el apartado anterior, a continuación se procede al análisis de cómo esas arquitecturas se engloban dentro de un sistema más amplio, desarrollando agrupaciones y generando intervenciones urbanísticas concretas.

\subsection{La horizontalidad como agrupación: un emplazamiento escarpado}

Formando parte de este grupo podemos considerar agrupaciones de las arquitecturas excavadas horizontalmente analizadas en apartados anteriores. Son aquellos casos en los que la excavación se ejecuta avanzando desde el frente de una montaña o acantilado, construyendo espacios habitables ahondando en sus paramentos verticales. Según sea la configuración natural que se aprovecha, podemos distinguir entre organizaciones lineales y organizaciones en anfiteatro.

\subsubsection{Agrupaciones lineales: pueblos acantilado}

Este tipo de agrupaciones es un caso extremo de configuración en ladera, situadas en zonas con una pendiente tan pronunciada, casi vertical, que se pueden considerar ya como parte de la pared de un acantilado. A diferencia de otros ejemplos, en este caso no se excava únicamente la roca, sino que además se buscan emplazamientos muy específicos bajo salientes naturales, dando lugar a pueblos completos situados en minúsculas repisas escarpadas.

Las cuevas en acantilado tenían un significado fundamentalmente defensivo, sin embargo, a la hora de la selección del emplazamiento, no olvidaron tener en cuenta escoger los acantilados con mejor orientación y lo más resguardados posible respecto a los vientos dominantes, beneficiándose, de este modo, de un microclima particular. Los ejemplos más conocidos de estas agrupaciones se encuentran en el sur de Estados Unidos, concretamente en Colorado, Utah, Arizona o Nuevo Méjico, aunque también existen otras agrupaciones interesantes en el valle de Zelva en Turquía, en los valles del Loira en Francia (Dordogne), en los valles de Viena y del Sena o en la India. En la Península ibérica podemos encontrar, al abrigo de esas cornisas naturales, construcciones populares aisladas en Cádiz (Setenil), Huesca (Monasterio de San Juan de la Peña) o Portugal (Monsanto). Cabe destacar el caso concreto de las cuevas de Almanzora en Andalucía, en las que existen hileras paralelas de excavaciones en la roca formando incluso viviendas de tres pisos en torno a grandes plazas públicas, en función de las condiciones del terreno.

Centrándonos en uno de los ejemplos más destacados dentro de estos «pueblosacantilado», existen unas espectaculares aglomeraciones troglodíticas en el Cliff Palace, ubicado en Mesa Verde, en la región de Colorado (EE.UU). Se trata de una agrupación excavada en la roca orientada hacia el sudoeste, con una cavidad de $100 \mathrm{~m}$ de longitud y 20 m de anchura que acoge más de 220 espacios, con una población de 250 habitantes aproximadamente. El grado de inclinación de la pendiente en la parte urbanizada es considerable, contando con un sistema de circulación exterior y de distribución de las viviendas muy interesante, en un emplazamiento que proporcionaba protección del sol del verano cuando alcanzaba $\operatorname{los} 40^{\circ}$ a la sombra, y de las bajas temperaturas del invierno con nevadas abundantes. 

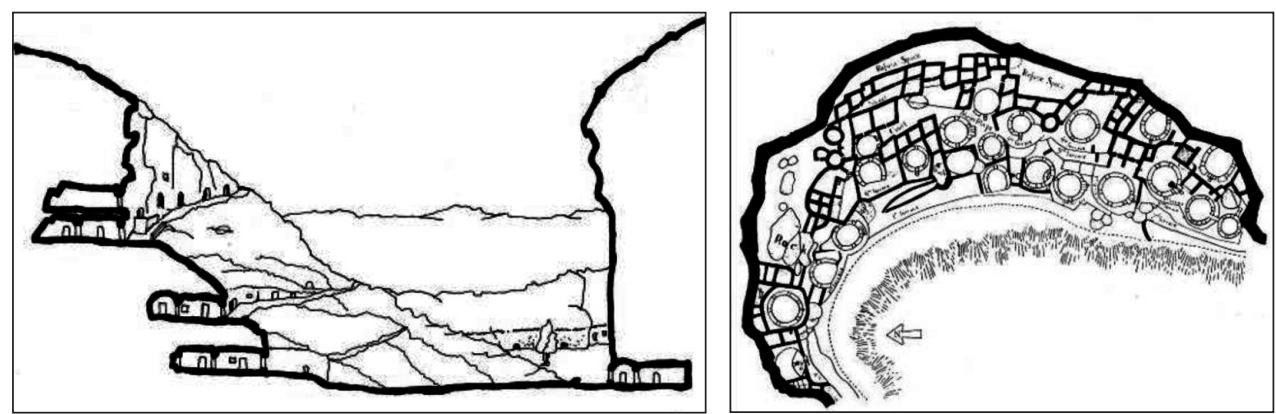

FIGURA 6: Imagen izquierda: Sección del barrio troglodita. Cuevas de Almanzora. Andalucía. España. Imagen derecha: Planta precipicios Cliff Palace. Colorado. EE.UU.

Fuente: Loubes (1985: 81 y 83).

\subsubsection{Agrupaciones circulares: pueblos en anfiteatro}

Este tipo de agrupaciones es otro de los ejemplos de configuraciones en ladera, que surge cuando los asentamientos se ubican en acantilados no desarrollados linealmente, sino describiendo una curva. En estos casos la especificidad de la morfología del lugar permite una disposición más centrada, que refuerza el aislamiento y la autonomía de la agrupación. Al contrario de lo que ocurría en el caso precedente en el que el elemento principal se basaba en la linealidad del conjunto, esta configuración viene determinada por un circo natural, dando lugar a un espacio central convergente, siendo los ejemplos más característicos los anfiteatros de Göreme y Cavusin (Turquía), aunque también existen agrupaciones en otros lugares como Chenini y Ghomrassen, ambos en Túnez. En el caso del circo de Göreme (Capadocia), se agrupan en una forma circular un gran número de iglesias y de establecimientos monásticos con sus anexos y celdas, reagrupando en una gran comunidad viviendas, servicios y refectorios de las comunidades religiosas.
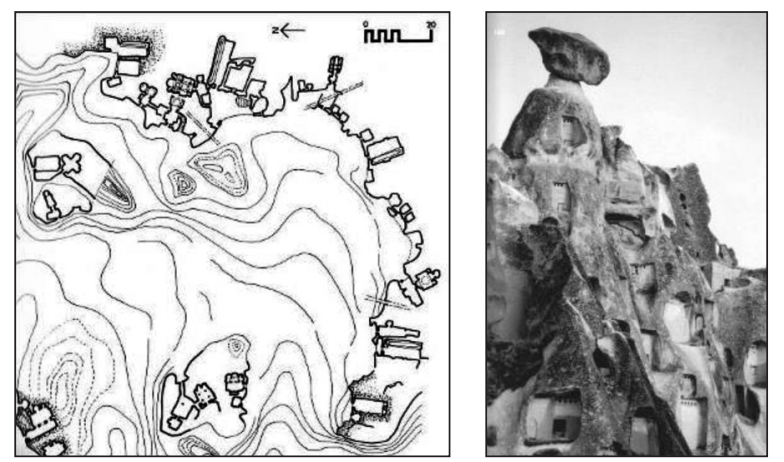

FIgURA 7: Imagen izquierda: Conos excavados en circos con iglesias rupestres en el centro. Circo del Göreme. Capadocia. Turquía. Fuente: Loubes (1985: 86). Imagen derecha: Viviendas troglodíticas. Valle del Göreme. Capadocia. Turquía.

Fuente: Omedes (2003: 133). 


\subsection{La verticalidad como agrupación: una planicie excavada}

Dentro de este apartado podemos encontrar pequeñas agrupaciones de viviendas subterráneas construidas bajo el subsuelo siguiendo una dirección de excavación completamente vertical, dando lugar a una de las primeras viviendas trogloditas, y por tanto siendo las más rudimentarias. Debido a esto, existen muy pocos ejemplos de esta arquitectura tan inicial, ya que este tipo de construcción pronto sufrió una evolución debido a la mejora de las herramientas de trabajo, dando paso a excavaciones mixtas que constituían intervenciones más complejas.

Estas excavaciones verticales eran muy elementales, primarias y poco efectivas, generando habitáculos de dimensiones reducidas, que necesitaban construcciones complementarias puesto que quedaban demasiado expuestos a la intemperie, siendo necesario proteger el hueco de acceso con una simple tapa o con una construcción en superficie.

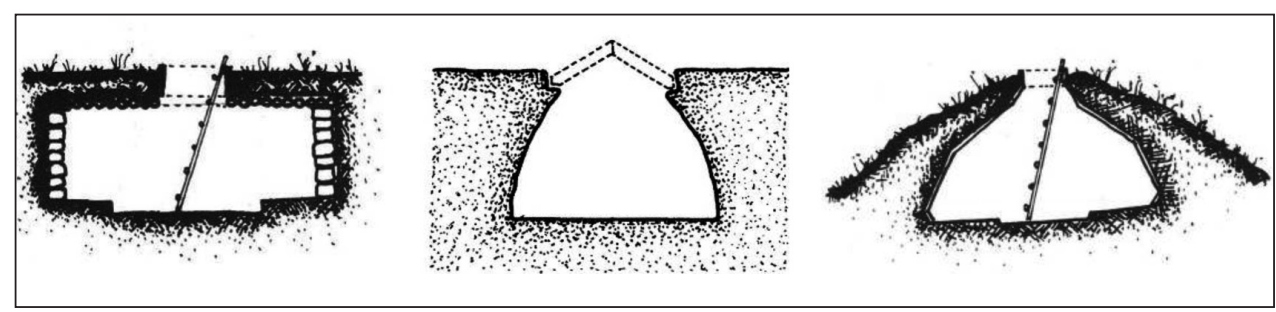

FIGURA 8: Imagen izquierda: Vivienda subterránea en Colorado. EE.UU. Fuente: Neila (2004: 400). Imagen central: Sección vivienda del neolítico excavada en «saco». Provincia de Shanxi. China. Fuente: Loubes (1985: 20). Imagen derecha: Casa esquimal de invierno. Alaska.

Fuente: Neila (2004: 400).

De este modo, una cueva recta, ejecutada verticalmente, responde a un hábitat primitivo, desprovisto de prestaciones efectivas, construido para dar un mínimo cobijo frente al viento o conservar víveres y pertenencias. Un refugio inicial, que podía ser usado como hábitat estable si se le añadía una cubierta exterior y un acceso básico.

Por contraposición a la construcción aditiva o por acumulación, en la que las huellas de anteriores edificaciones existentes en el lugar forman parte de las nuevas construcciones ya sea física o conceptualmente hablando, en la arquitectura excavada no es posible un estudio arqueológico tal y como se entiende hoy en día, puesto que la construcción no se apoya en restos anteriores, añadiendo capas, sino que por el contrario se extrae lentamente el material, esculpiendo y tallando los rastros remanentes de las construcciones previas. No existe así un poso arquitectónico previo a conservar, puesto que los espacios se ensanchan, destruyendo en cierto modo su configuración primitiva y borrando su memoria física aunque no su esencia, dejando libre a la imaginación cualquier hipótesis espacial previa. A este respecto, Algarín (2006: 36) afirma: «Los suelos no suben de cota con la inevitable sucesión de civilizaciones sino que bajan, permaneciendo siempre al aire la roca que se excava o pule. Tenemos así una visión de ciudades ideales que, a pesar de estar formadas de vacío, parecen ser enormemente pesadas porque se hunden lentamente en la roca con el paso del tiempo. Su centro, la parte más antigua, aparecería de esta forma deprimido en su perfil visto desde la distancia, en vez de resaltado como consideramos natural». 


\subsection{La ingravidez como agrupación: un paisaje defensivo}

A este tipo de agrupación pertenecen aquellas arquitecturas que desarrollan excavaciones en elementos rocosos superficiales, como es el caso de los pueblos trogloditas en los conos de Capadocia (Turquía), quienes utilizan los montículos naturales preexistentes en el entorno para ubicar sus viviendas, seleccionando aquellos puntos estratégicos según los intereses de un tejido global que organiza la estructura del pueblo. Se trata de una actuación sustractiva puesto que se excava sobre la propia configuración natural, desembocando en un urbanismo en superficie, por encima de la línea de tierra.

Por tanto, es en la región de Anatolia donde se vieron nacer algunas de las civilizaciones más antiguas del mundo, ya que desde la prehistoria, las cuevas naturales de Capadocia, gracias a su accidentado relieve, han posibilitado refugio a poblaciones que huían de sucesivas oleadas de invasores, tal y como testimonian las localizaciones arqueológicas como Catalkáyük, fundada aproximadamente en el 6500 antes de Cristo.

El aspecto formal tan característico del conjunto urbano es el resultado del material del entorno, una toba de orígen volcánico que, debido a la erosión del viento, da lugar a unas formas naturales muy singulares. Estas formas han acogido de manera específica una arquitectura y un urbanismo rupestre, y con el paso del tiempo, también han acogido a distintas civilizaciones, sirviendo como refugio para sociedades tan diferentes como la hitita, la griega, la romana, la cristiana o la otomana, donde la geografía natural tan escarpada y singular permite que se genere otro sistema relacionado con la condición defensiva de la colectividad. La ocupación de esas «torres vigía» naturales, es un modo interesante de percibir y controlar el territorio, convirtiéndose en un lugar propicio para un desarrollo excavado en altura.
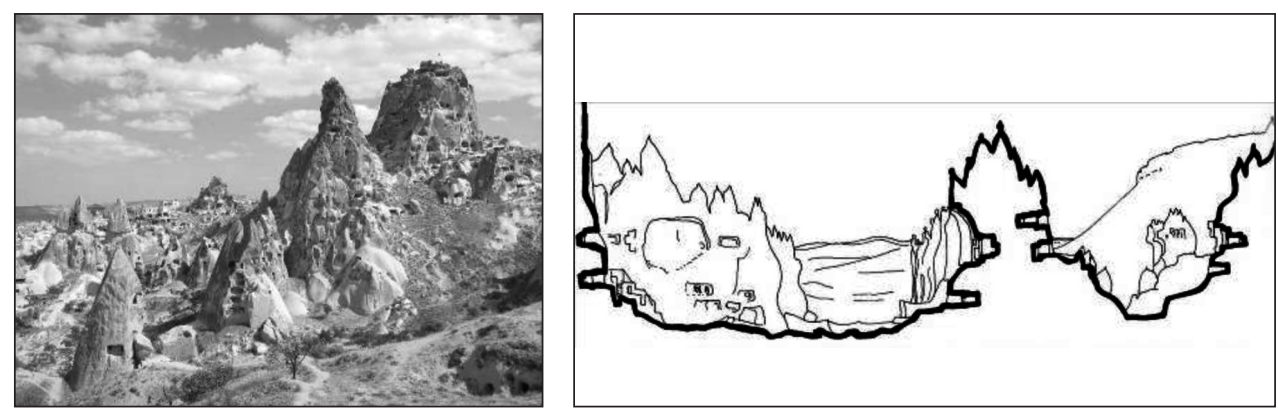

FIGURA 9: Imagen izquierda: Viviendas excavadas en conos. Capadocia. (Turquía). Fuente: www.panoramio.com. Imagen derecha: Sección de los Valles del Zelve. Capadocia. (Turquía). Según Arts de Cappadoce. Ed. Nagel. Ginebra, 1971.

Fuente: Loubes (1985: 82).

De este modo se excavan espacios con uso vivienda, pero además existen gran cantidad de iglesias rupestres o ermitas, ocupando conos y naciendo de esta forma aglomeraciones de población. Las viviendas, de planta cuadrada rectangular, compacta y cerrada al exterior, suelen tener dos o más niveles conectados interior o exteriormente. En la planta de acceso se encuentran el dormitorio y la sala de visitas y el resto son estancias más privadas, todas 
ellas con una altura de aproximadamente tres metros. Debido a que en la zona el agua escasea, no existen baños en el interior de las viviendas, y la única estancia un poco más acondicionada en las excavaciones es la sala de visitas. El resto de los espacios conservan el color y acabado del material natural donde se disponen, el de la toba volcánica.

\subsection{La complejidad como agrupación: una metróploli subterránea}

Varios ejemplos construidos se pueden englobar dentro de este tipo de agrupaciones troglodíticas, siendo las dos más importantes las grandes ciudades subterráneas de Kaymakli y Derinkuyu, en la meseta de Capadocia, región central de Anatolia (Turquía), aunque posiblemente, según distintas investigaciones, todavía existan más de 30 ciudades aún por descubrir en la zona, muchas de ellas comunicadas entre sí. En estas agrupaciones, las exigencias defensivas han derivado hacia una solución mucho más extrema que las anteriores, llevando a las viviendas hacia un enterramiento total. Son ciudades soterradas con una importante función defensiva, ubicadas en una región extensa, irregular y árida.

En estas regiones, el suelo está compuesto por toba volcánica procedente de las erupciones de los volcanes circundantes que estuvieron activos en la zona hace tres millones de años. Un material bastante blando y manejable, mezcla de lava, ceniza y barro, que da lugar a paisajes de conos rocosos erosionados por el viento y muy fáciles de trabajar con escasas herramientas, como hemos visto específicamente en el apartado anterior. Esta roca en contacto con el aire endurece, proporcionando resistencia suficiente para seguir la excavación si se hace con la suficiente lentitud como para asegurar el endurecimiento. Un proceso bastante pausado si se tiene en cuenta que, según distintos autores, la excavación de un local podía tardar unos tres años.

La ciudad subterránea de Kaymakli en Capadocia, fundada con ese nombre en el siglo VII, se ubica en este tipo de suelo volcánico y es una agrupación que se comienza a construir hacia siglo I en una zona con unas condiciones naturales especialmente propicias, con el objetivo de erigirse como una ciudad fortificada para la defensa frente a persecuciones políticas, religiosas o invasiones de sus vecinos más fuertes: persas, macedonios y romanos, y posteriormente, de la opresión islámica en el siglo VII.

Esta ciudad excavada podía albergar unas 20.000 familias, llegando a ocupar hasta diez niveles bajo el subsuelo, extendiéndose a través de varios kilómetros y desarrollando un urbanismo subterráneo de defensa. Los distintos espacios, de dimensiones extremadamente variadas según sus funciones, estaban ligados por una red de galerías interconectadas que, en caso de necesidad, podían obstruirse rodando pesados discos de roca que aislaban a la población de un posible agresor.

La comunicación con el exterior sólo se realizaba entonces puntualmente a través de algún acceso muy localizado y vigilado y por orificios de ventilación.

En este tipo de ciudades subterráneas la organización es muy compleja, llegando a contar con plazas, almacenes, molinos, prensas, reservas de provisiones, iglesias, cementerios, acondicionados mediante una red de conductos de ventilación. Esta organización servía propiamente como sistema defensivo, al tiempo que permitía un desarrollo productivo asegurando a los pobladores un largo período de autonomía.

Por otra parte, la ciudad excavada de Derinkuyu se construye en ocho niveles subterráneos y su zona más baja se asienta a unos ochenta metros bajo la superficie. Estaba compuesta por todos los espacios requeridos para la vida en total aislamiento gracias a la construcción de molinos, prensas, aljibes o silos para el almacenamiento de provisiones, al mismo tiempo que existían espacios de relación como calles, plazas, iglesias o mercados 
donde se desarrollaba la economía de sus habitantes al tiempo que estaban defendidos y protegidos durante grandes periodos. Se estima que esta ciudad albergó a unos diez mil habitantes dentro de este gran complejo similar a la estructura de un hormiguero, en el que se observa cómo en muchos puntos se intersectan estancias, ampliándose hasta encontrarse unas con otras. De este modo, aparece una organización urbana compleja, fruto de un trabajo continuado en el tiempo, en la que abriendo una serie de pasadizos y corredores inclinados de escasas dimensiones se unen habitaciones de familiares o espacios comunes, divididos en secciones estancas separadas como sistema defensivo.
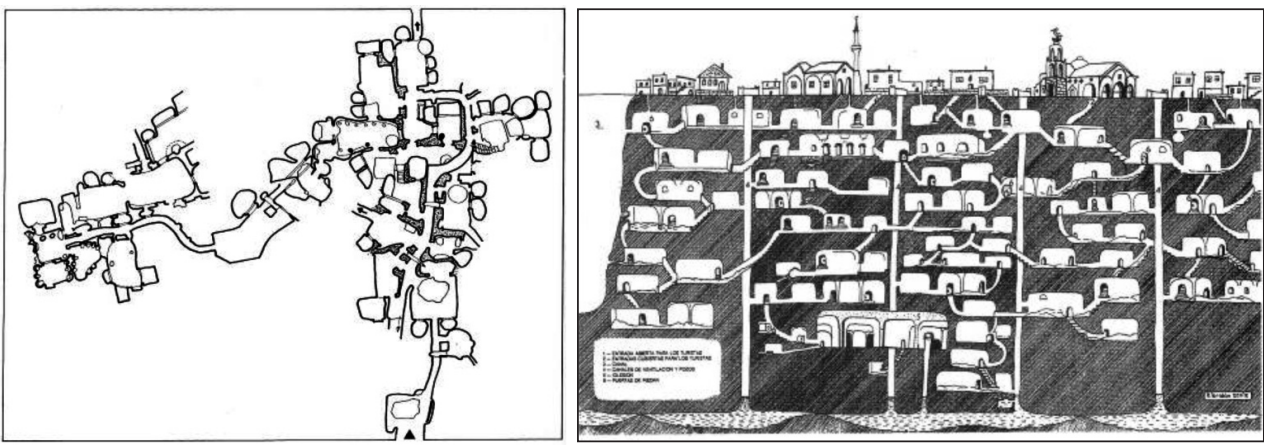

FIgURA 10: Imagen izquierda: Planta parcial de ciudad subterránea. Kaymakli. Capadocia. (Turquía). Fuente: Loubes (1985: 90). Imagen derecha: Derinkuyu. Ciudad subterránea en Capadocia. (Turquía).

Fuente: Neila (2004: 82).

También es interesante decir que la arquitectura subterránea en zonas de temperaturas extremas como ésta, favorece la regulación de las condiciones climáticas de las viviendas, proporcionando una gran estabilidad térmica gracias al terreno donde se excavan. Estas construcciones poseen una gran inercia térmica por estar completamente enterradas y respecto al aislamiento térmico la toba volcánica es una roca de baja conductividad térmica. De este modo, las estancias consiguen una temperatura perfecta tanto para habitar como para un buen almacenamiento de alimentos, algo imprescindible también para la autosuficiencia durante largos períodos temporales, ya que según Neila (2004: 82): «A una profundidad de 50 a $150 \mathrm{~cm}$ la temperatura es constante y coincide con la media diaria, y a partir de 10 ó 15 m coincide con la media anual. Unicamente las capas más superficiales se ven directamente afectadas por los fenómenos climáticos».

\section{Conclusiones}

En conclusión, respecto a la arquitectura troglodita cabe decir que existen múltiples ejemplos que responden a distintas combinatorias tipológicas puesto que los arquitectos trogloditas han intentado adaptar al máximo disposiciones elementales enriqueciendo enormemente el resultado. Este juego combinatorio de excavación horizontal y vertical, que en un principio podría insinuarse como parte de una situación azarosa, puede respon- 
der a motivos climáticos que requiriesen mayor protección o a motivos técnicos debidos al desarrollo de nuevas herramientas o conocimientos. En palabras de Loubes (1985: 40) se pueden llegar a evidenciar en algunos casos arquitecturas estratificadas y superpuestas o incluso motivos arquitectónicos que desarrollan la expresividad de pasar " [...] de lo excavado a lo construido, de lo subterráneo a lo superficial. De lo visible a lo oculto, de lo oscuro a lo luminoso».

En definitiva, los pueblos excavados constituyen un atractivo ejemplo de urbanismo subterráneo que ha logrado resolver de un modo muy interesante la abertura de las construcciones hacia el clima exterior logrando un beneficio térmico gracias, bien a la inercia térmica de grandes muros de terreno natural o bien mediante la creación de espacios colchón, tal y como ocurre con la generación de los pozos centrales en las arquitecturas excavadas. Espacios que, al tiempo que distribuyen y organizan las habitaciones de la vivienda, aseguran la penetración indirecta de la luz y el calor de un modo muy confortable.

Dentro de estas tipologías de excavación se pueden encontrar diferentes subtipos, algunos de ellos centrados únicamente en la excavación de terrenos existentes, como los estudiados en el presente trabajo, mientras que otros se basan en el aporte de ciertos materiales a la excavación. Según Algarín (2006: 43): «Modelos híbridos que en muchos casos intentarán tranquilizar al usuario camuflando su realidad sustractiva para parecerse a la arquitectura «construida», y en otros, pese a ser una construcción claramente tectónica, seducidos por los sorprendentes espacios excavados, imitan sus resultados». Por tanto, cabe destacar que, contrariamente a lo que ocurría en las tipologías anteriores en las que la excavación era el elemento protagonista, existen también otras arquitecturas excavadas mixtas en las que no sólo predomina la extracción de material, sino que al mismo tiempo se combina ese proceso con un aporte de otros elementos, normalmente tierra, para intentar modificar el relieve existente. Construcciones excavadas que se combinan con otras aditivas, capaces de generar estructuras más complejas y de crear fuertes relaciones entre espacios con una creación conceptual distinta.

Por otro lado, concluyendo al respecto del urbanismo troglodita, y aunque a lo largo de la evolución humana ha existido una extensa variedad de formas sociales y organizaciones de ciudades, ciertos conceptos básicos comunes a todos los pueblos vernáculos pueden ser identificados de forma global. La gran variedad de agrupaciones observadas es fiel testimonio de la facultad de adaptación de la arquitectura troglodítica a las condiciones propias del terreno, de la topografía y del clima, teniendo en cuenta que las potencialidades del emplazamiento condicionan más la forma de agrupación que la función de los mismos edificios existiendo ejemplos excavados de viviendas, elementos defensivos o lugares de culto.

Cabe destacar que según Goldfinger (1993: 152) una de las características principales que identifican a un pueblo es su relación con el medio natural, ya que se hace necesario un vínculo con el entorno, alcanzando un equilibrio con la naturaleza, ya sea amoldando de un modo sumiso la estructura humana a un territorio complejo y con carácter, como pudiera ser el caso de Matmata (Turquía), o bien imponiendo lo artificial ante un territorio sin accidentes ni impedimentos, como ocurre en Luoyang (China). Así, se puede concluir que, contrariamente a lo que pudiera parecer, y según Schoenauer (1984: 27): «[...] Se puede predecir que las sociedades más sencillas ocupan las regiones menos deseables y, en cambio, las más complejas, las zonas más favorecidas».

Finalmente, es necesario apuntar que el presente trabajo es muestra de la primera fase de un proyecto global que trata de estudiar y valorar la trascendencia de la arquitectura troglodítica a una escala mundial, nacional y regional; y cómo determinadas soluciones propuestas en ella pueden ser trasladables a la arquitectura y al urbanismo en la actualidad. 
Tras el presente estudio, aquí mostrado, de la evolución de la arquitectura primitiva excavada a nivel internacional, en la actualidad se está llevando a cabo una investigación pormenorizada de las diferentes soluciones existentes en España y de sus implicaciones concretas en la geografía regional, con el fin de poder aplicar, en una tercera fase del proyecto, las conclusiones obtenidas a actuaciones reales concretas en regiones del sureste peninsular.

\section{Agradecimientos}

La autora desea agradecer al profesor Vicente Gozálvez Pérez las consideraciones realizadas. El presente trabajo forma parte de la tesis doctoral de la autora.

\section{Bibliografía}

AA.VV. (1989): Arquitectura subterránea. Tomos I y II. Consejería de Obras Públicas y Transportes. Junta de Andalucía.

AA.VV. (1993): Cobijo. Tursen Hermann Blume Ediciones. Madrid.

ALGARÍN COMINO, Mario (2006): Arquitecturas excavadas. El proyecto frente a la construcción de espacio. Colección Arquíthesis, num.21. Fundación Caja de Arquitectos. Barcelona.

ARAZO, M Ángeles; JARQUE, Francesc (1995): Arquitectura popular valenciana. Diputación Provincial de Valencia. Valencia.

DEFFONTAINES, Pierre (1980): L'homme et sa maison. Collection Géographie Humaine. Éditions Gallimard. Mayenne.

ELÍAS PASTOR, Luis V.; MONCOSÍ DE BORBÓN, Ramón (1978): Arquitectura popular de La Rioja. Ministerio de Obras Públicas y Urbanismo. Madrid.

FEDUCHI, Luis (1974): Itinerarios de Arquitectura Popular Española. Colección Nueva Imagen. Editorial Blume y Editorial Labor. Barcelona.

GARCÍA AZNAR, José Antonio; LÓPEZ DAVÓ, Joaquín Antonio (2000): Las cuevas de Crevillent. Estudio y catálogo gráfico. Instituto de Cultura Juan Gil-Albert y Ayuntamiento de Crevillente. Alicante.

GARCÍA MERCADAL, Fernando (1981): La casa popular en España. Colección Punto y Línea. Gustavo Gili. Barcelona.

GOLDFINGER, Myron (1993): Arquitectura popular mediterránea. Gustavo Gili. Barcelona.

GONZÁLEZ PRATS, Alfredo (1983): Estudio arqueológico del poblamiento antiguo de la Sierra de Crevillente. Universidad de Alicante. Alicante.

GONZALO, Guillermo Enrique (2004): Manual de Arquitectura Bioclimática. Editorial Nobuko. Tucumán.

GOZÁLVEZ PÉREZ, Vicente (1971): Crevillente. Estudio urbano y demográfico. Departamento de Geografía Universidad de Valencia. Valencia.

GOZÁLVEZ PÉREZ, Vicente (1983): Crevillente. Estudio urbano, demográfico e industrial. Instituto Universitario de Geografía Universidad de Alicante. Alicante.

GOZÁLVEZ PÉREZ, Vicente (1977): El Bajo Vinalopó. Geografía agraria. Departamento de Geografía Universidad de Valencia. Valencia.

LOUBES, J.P (1985): Arquitectura subterránea. Aproximación a un hábitat natural. Colección Tecnología y Arquitectura. Gustavo Gili. Barcelona.

NEILA GONZÁLEZ, F. Javier (2004): Arquitectura bioclimática en un entorno sostenible. Colección Arquitectura y Tecnología. Editorial Munilla-Lería. Madrid.

OLIVER, Paul (2007): Dwellings : the vernacular house world wide. Editorial Phaidon. Hong Kong.

OMEDES, Anna; PIQUÉ, Josep (2003): Los otros arquitectos. Catálogo de exposición. Museu de les Ciències Naturals de la Ciutadella. Gustavo Gili. Barcelona.

RUDOFSKY, Bernard (2002): Architecture without architects. A short introduction to non-pedigreed architecture. University of New Mexico Press. Albuquerque. 
SORIANO ALFARO, Vicent (2006): Arquitectura de tierra en el sur de Marruecos. El oasis de Skoura. Colección Arquíthesis, num.18. Caja de Arquitectos. Barcelona.

SHOENAUER, Norbert (1984): 6.000 años de hábitat. De los poblados primitivos a la vivienda urbana en las culturas de oriente y occidente. Colección Arquitectura/Perspectivas. Gustavo Gili. Barcelona.

TORRENOVA, J.J.: Las cuevas de Guadix, Granada. Revista Arquitectura, núm. 193. Colegio Oficial de Arquitectos de Madrid, Madrid, 1975.

URDIALES VIEDMA, Ma Eugenia: Cuevas de Andalucía. Evolución, situación y análisis demográfico en la provincia de Granada. Colección Monografía 3. Tomos I y II. Consejería de Obras Públicas y Transportes. Granada, 1987. 
